\title{
ALIANZAS PÚBLICAS PRIVADAS Y SU APORTACIÓN AL CAMBIO DE LA MATRIZ PRODUCTIVA DEL ECUADOR
}

PUBLIC PRIVATE PARTNERSHIPS AND ITS CONTRIBUTION TO THE PRODUCTION AGENDA OF ECUADOR incrementar los flujos de inversión extranjera privada hacia nuestro país, con el propósito de generar plazas de trabajo y constituir negocios sustentables cumpliendo con el Décimo Objetivo del II Plan Nacional del Buen Vivir que busca cambiar la matriz productiva, pasando de una economía exportadora de productos básicos a una economía generadora de productos y servicios con alto valor agregado. La propuesta consiste en explicar una modalidad de inversión que permita compartir el riesgo de invertir entre el inversionista privado y el Gobierno Central, considerando que el segundo participante tiene levantados proyectos que buscan capitales provenientes de inversionistas extranjeros.

PaLabras CLAVE: alianzas públicas y privadas, inversión extranjera directa, desarrollo de negocios, cambio de la matriz productiva, sectores estratégicos.

\begin{abstract}
The purpose of the articles is to analyze and propose strategies which aims to increase the inflows of private foreign investment directed into Ecuador with the purpose of increase job opportunities and develop sustainable businesses by fulfilling the objectives defined in the II Good Living Plan specifically the 10th objective which aims to transform the Production Matrix of Ecuador by exporting value added products instead of basic agricultural and non renewable commodities. The proposal aims to explain the investment stake between private corporate investor and the Ecuadorian Government who already have projects developed which are seeking capital from foreign investors.
\end{abstract}

KEYWORDS: public private partnerships, foreign direct investment, business development, strategic sectors. 
INTRODUCCIÓN

Uno de los retos más importantes planteados por el Gobierno Nacional de la República del Ecuador es cambiar la forma de producción. Se necesita empezar por cambiar la mentalidad de exportar materias primas a una economía global generadora de valor agregado los cuales indudablemente mejorarán márgenes de ganancias, generarán plazas de trabajo y priorizarán la industria nacional con miras a exportar a mercados internacionales.

Lo anteriormente planteado se encuentra plasmado en el "II Plan Nacional del Buen Vivir" (2013-2017), elaborado por la Secretaría Nacional de Planificación (SENPLADES), en conjunto con la Presidencia, Vicepresidencia, Ministerio Coordinado de la Producción, Sectores Estratégicos, entre otras instituciones, las que son las encargadas de diseñar políticas productivas necesarias, con el propósito de reactivar al sector micro, macro empresarial y a los nuevos participantes conocidos como los actores de la Economía Popular y Solidaria (EPS).

Es meritorio conocer ¿cómo se define a la inversión? Consiste en un intercambio de dinero entre dos partes. La primera tiene un exceso de capital el cual está dispuesto a comprometerlo en un negocio con el propósito de obtener una rentabilidad sobre el mismo por un período de tiempo. Con relación al segundo participante, recibirá el dinero por parte del inversionista permitiéndole comprar activos fijos y cubrir problemas de liquidez con el fin de elaborar productos o servicios los cuales serán ofrecidos al público, generando ventas y consecuentemente pagos al inversionista vía dividendos, intereses o ganancias de capital. La razón fundamental por la cual las dos partes se juntaron, fue la confianza mutua generada antes de la transacción. El primero apuesta a que su inversión generará rentabilidad monetaria y el segundo recibirá los fondos permitiendo establecer o potenciar negocios que generarán plazas laborales.

La realidad actual del sector industrial ecuatoriano difiere del pasado dado que existe una fuerte distorsión en el sector productivo privado local el cual restringe la inyección de nuevos recursos hacia sectores productivos. Se hace referencia a las palabras del ingeniero Henry Kronfle (2013), presidente de la Cámara de Industrias de Guayaquil en declaraciones hechas al portal de noticias electrónica "Ecuador Inmediato" con fecha 20 de mayo del 2013 en donde dice "Nadie invierte en el país por decreto, sino como resultado de la confianza" y este es un punto importante de resaltar dado que todo inversionista que arriesga su capital, necesita un ambiente de negocios estable donde no cambien las reglas de juego dada la caída del precio del petróleo y materias primas que se negocian en mercados internacionales, y que el país se ha vuelto experto en producirlos durante los últimos cuarenta años.

En lo concerniente a la estructura productiva del país, principalmente se encuentra dividida en dos sectores: el primero está integrado por los sectores estratégicos los cuales comprenden la generación de energía en todas sus formas, recursos naturales no renovables, refinación de hidrocarburos, manejo de agua, telecomunicaciones y espectro electromagnético (Constitución, 2008, Art 313).

Históricamente parte de estos sectores han recibido grandes flujos de inversión privada con el fin de explotarlos y exportarlos sin ningún tipo de proceso de industrialización.

El segundo sector productivo se le conoce como Priorizados y comprende 18 sectores de los cuales, nueve inquieren generar valor agregado dentro de la economía nacional y los nueve restantes buscan sustituir selectivamente importaciones mediante el desarrollo de industrias claves (Código Orgánico de la Producción, Comercio e Inversiones, COPCI, 2010, Libro IV Art 236, Disposición Reformatoria 2.2). Corresponde mencionar que algunos de los sectores como turismo, reforestación, alimentos procesados, agroindustria, metalmecánico, autopartes, desarrollo de software, hardware, línea blanca, entre otros. Es importante resaltar que el segundo sector productivo busca ser el ente dinamizador de la economía, permitiendo el desarrollo de nuevos negocios dada la normativa existente en materia de incentivos tributarios detallados en el COPCI.

La inversión productiva extranjera captada por el país hacia los diferentes sectores mencionados, indica una clara tendencia negativa, considerando que posterior al 2008 no se ha podido captar el monto de inversión privada obtenida en ese año en particular (figura 1). Uno de los factores preponderantes fue la denuncia de todos los Tratados Bilaterales de Inversión (TBI) por parte de la Asamblea Constituyente de Montecristi (Constitución, 2008, art. 422) dado que todo arbitraje y mediación entre el gobierno ecuatoriano y empresas transnacionales por concepto de problemas de repatriación de utilidades, tributación, venta de activos, entre otros, fueron ventilados en instancias internacionales ajenas a la soberanía ecuatoriana. 


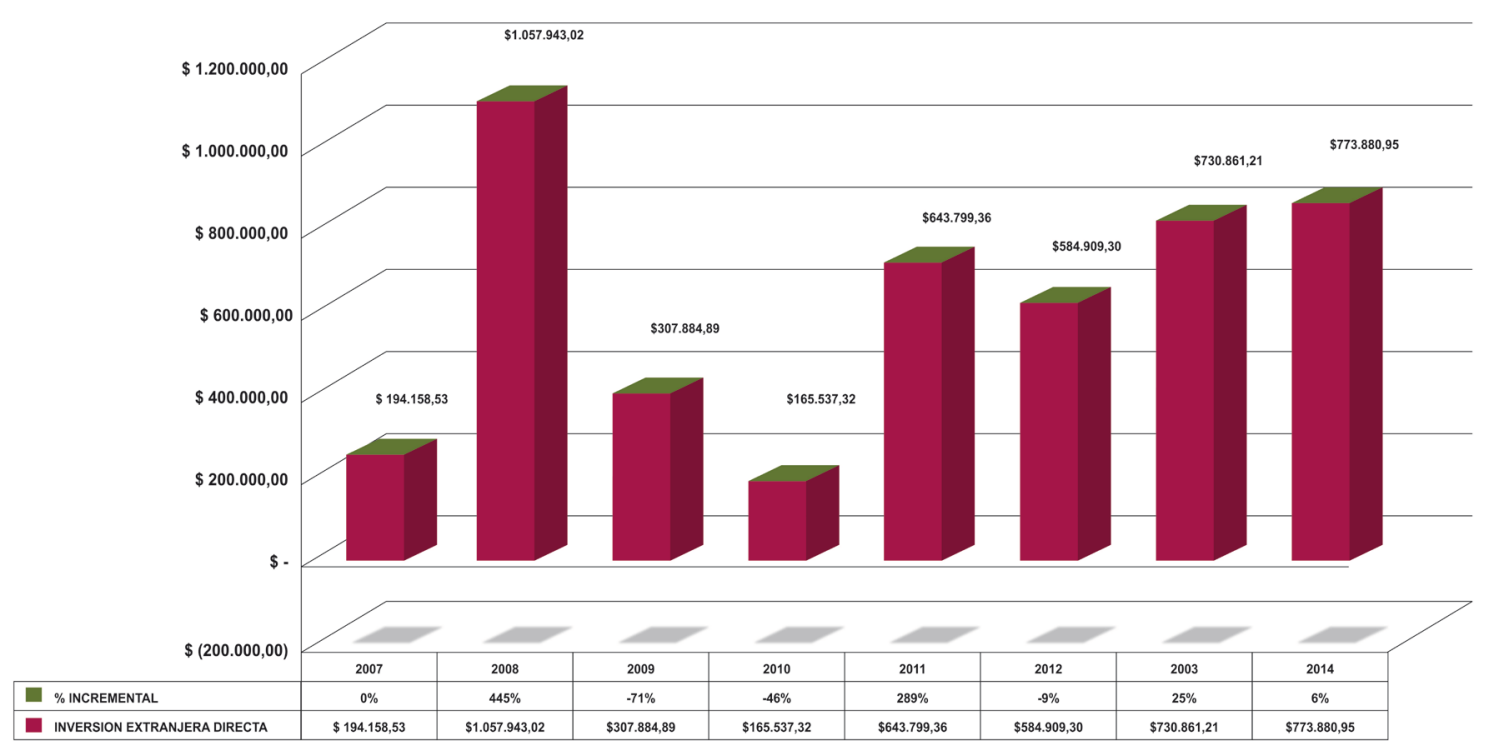

Figura 1. Comportamiento de los flujos de inversión Extranjera Directa recibida por el país.

Fuente: Banco Central del Ecuador, años 2007 - 2014.

La denuncia de los TBI ha creado un panorama adverso al inversionista extranjero dado que ha reducido su confianza en arriesgar capitales frescos enfocados en el desarrollo de nuevos negocios o en la reinversión de utilidades generadas por negocios previamente establecidos en nuestro país. En ese sentido, el empresario se ve en la obligación de pagar un "peaje" del $5 \%$ por girar sus utilidades al extranjero siendo este castigo conocido como el Impuesto a la Salida de Divisas (ISD).

\section{PROPUESTA}

La solución ante esta problemática es juntar al inversionista privado extranjero, quien está dispuesto en poner capitales financieros y al Estado ecuatoriano, quien es el encargado de diseñar proyectos financieros y socialmente rentables mediante la creación de Alianzas Públicas y Privadas (APP).

Esta modalidad de inversión permite compartir el riesgo, dado que los recursos financieros necesarios para la consecución del proyecto provienen tanto del inversionista privado como del gobierno nacional. Al compartir las fuentes de inversión, la participación accionaria permitirá que el inversionista genere y pague utilidades a sus socios sobre su participación, y que el gobierno obtenga recursos sin la necesidad de cobrar nuevos impuestos sobre el negocio administrado en conjunto.
A continuación se detallan potenciales beneficios de establecer APP en nuestro país:

- Libera recursos del presupuesto general del Estado destinado a la construcción de proyectos en la línea de Estratégicos. Según el Plan Anual de Inversiones (PAI) del Gobierno Nacional (Redacción Económica Diario El Telégrafo), para el 2015 se estima una inversión total de 8.116 de millones de dólares, de los cuales el $32 \%$ está destinado a cubrir proyectos en infraestructura e industrias básicas ( $\mathrm{Re}^{-}$ dacción Económica, Diario el Telégrafo, 26 de febrero del 2015). Al permitir la creación de APPS, el inversionista podrá inyectar capitales en proyectos estratégicos y consecuentemente el Gobierno Nacional reasignará esos recursos inicialmente presupuestados, a otros sectores claves como salud, educación y seguridad. Es importante mencionar que el Presidente de la República mediante decreto № 582 aprobó el Reglamento del Régimen de Colaboración Público-Privada, el cual permite una vinculación directa entre inversionistas locales y extranjeros con el Estado el cual es conocido como Promotor Público.

- Dinamiza la emisión de títulos bursátiles mediante la venta de acciones 
comunes, deuda a largo plazo o ambos en bolsas mercantiles de Guayaquil y Quito. La participación privada de los proyectos estratégicos se negociarán libremente y se transparentará la información mediante reuniones periódicas entre los accionistas y gerentes encargados. También existe la opción de emitir títulos del Registro de Valores No Inscritos en el Mercado (REVNIS) los cuales reducen los tiempos de trámite necesarios para el proceso de emisión pública y la consecuente captación de recursos (Ley Orgánica para el Fortalecimiento y Optimización del Sector Societario y Bursátil, 2014).

- Concede una exoneración del impuesto a la renta por un período de diez años siempre y cuando las nuevas inversiones productivas se realicen fuera de los perímetros urbanos de Guayaquil y Quito (Ley Orgánica de Incentivos a la Producción y Prevención de Fraude Fiscal, 2014 y COPCI). Una de las industrias básicas que se beneficiará de este incentivo será el complejo petroquímico a construirse dentro de proyecto Refinería del Pacífico ubicado en la zona de El Aromo, Manta, provincia de Manabí (Ministerio Coordinador de los Sectores Estratégicos, 2015).

- Permite que los dólares que ingresan al país se inviertan en proyectos, los cuales generarán rentabilidades en la misma moneda, reduciendo el riesgo de devaluación asumido por el inversionista si realizara inversiones en países vecinos.

- Ofrece oportunidades de inversión a fondos provisionales y cesantías locales los cuales buscan obtener ganancias a largo plazo mediante el ahorro mensual por parte de sus aportantes.

- Concede la suscripción de Contratos de Inversión entre el inversionista extranjero y el Estado Ecuatoriano ofreciendo estabilidad tributaria por un período de 15 años y resolución de conflictos en instancias internacionales (COPCI, 2010, Libro II Art. 25 -27). Estos contratos son canalizados por el Secretario Técnico del Ministerio Coordinador de la Producción, Empleo y Competitividad (MCPEC) y representan una opción para la solución de futuros conflictos en instancias internacionales donde no se atente con la soberanía del país.
- Propicia el uso de nuevas tecnologías beneficiando a empresas públicas encargadas de formular y administrar proyectos estratégicos. Existen casos de éxitos de empresas chinas las cuales comenzaron como iniciativas gubernamentales y crecieron hasta convertirse en empresas transnacionales como Build your Dreams (ByD Productora y ensambladora de carros); Huawei, empresa proveedora de equipos de telecomunicación; China National $\mathrm{Pe}^{-}$ troleum Corporation (CNPC) una de las empresas más grandes en exploración y explotación hidrocarburífera en el mundo; y Ali Baba, Portal electrónico el cual ofrece diferentes servicios en línea permitiendo transacciones entre empresarios individuales y corporativos chinos con compradores internacionales. Esta última empresa logró captar 25 mil millones de dólares mediante una oferta pública autorizada de acciones comunes en la Bolsa de Valores de Nueva York según Picker, L y Chen, L (2014).

\section{CONCLUSIONES}

Es imperativo mencionar que el sector académico ecuatoriano siempre estará dispuesto a crear espacios de diálogo donde se puedan aportar con propuestas claras y concretas en pro de mejorar las condiciones del sector empresarial ecuatoriano.

El ambiente económico actual permite que la academia genere sinergias dejando de lado desacuerdos políticos, los cuales merman el cumplimiento de los objetivos de mejora productiva, trazados en la Agenda de Transformación Nacional.

La implementación de este modelo que permite la coparticipación entre el Cobierno Nacional y el inversionista privado local/extranjero, permitirá la entrada de capitales frescos los cuales reemplazarán los flujos de inversión extranjera pública vía deuda colaterizada, adquiridas por el país durante los últimos cinco años principalmente de la República Popular de China. Esta última, ha sido la primera fuente de financiamiento de proyectos en materia de infraestructura hidroeléctrica y explotación hidrocarburífera/minera.

En la actualidad existe la normativa legal que permite la coexistencia entre la empresa privada y el Gobierno Nacional mediante la expedición de la Ley Orgánica de Incentivos para Asociaciones Publico-Privadas y la Inversión 
Extranjera, aprobada por la Asamblea Nacional el 15 de diciembre de 2015 y publicada en el Registro Oficial, número 652.

REFERENCIAS BIBLIOGRÁFICAS

Banco Central del Ecuador. (2007-2014). Inversión extranjera directa reportada en la balanza de pagos: Inversión extranjera directa por rama de actividad económica. Recuperado de http://www.bce. fin.ec/index.php/component/k2/item/298inversi $\%$ C $3 \%$ B3n-extranjera-directa.

Código Orgánico de la Producción, Comercio e Inversiones COPCI. (2010) Quito Distrito Metropolitano: Registro Oficial N. 351.

Constitución de la República del Ecuador. (2008). Ciudad Alfaro Montecristi, Manabí: Registro Oficial N. 449.

"Henry Kronfle pide reformas a Código de la Producción y que Sede del Ministerio de Comercio sea en Guayaquil". (20 de mayo del 2013). Portal de Noticias Ecuador Inmediato. Recuperado de http://ecuadorinmediato.com/ index.php? module $=$ Noticias\&func $=$ news user_view\&id=197308\&umt=henry_kronfle pide_reformas_a_codigo_produccion_y_que _ sede_del_ministerio_comercio_sea_en_guayaquil.

Ley Orgánica de Incentivos a la Producción y Prevención de Fraude Fiscal. (2014) Quito Distrito Metropolitano: Registro Oficial N. 405.
Ley Orgánica para el Fortalecimiento y Optimización del Sector Societario y Bursátil. (2014). Quito Distrito Metropolitano: Registro Oficial N 249.

Ministerio Coordinador de los Sectores Estratégicos (2015). Catálogo de Inversiones de los Sectores Estratégicos (2015-2017) Parte 1. Recuperado de http://www.sectoresestrategicos. gob.ec/biblioteca/.

Picker, Leslie y Lulu, Chen. (2014). Oferta Pública Autorizada de Ali Baba logra recaudar 25 mil millones de dólares. Nueva York, EEUU. Bloomberg Business. Recuperado de http://www.bloomberg. com/news/articles/2014-09-22/alibaba-sbanks-said-to-increase-ipo-size-to-record25-billion.

Redacción Económica. (26 de febrero de 2015). Se reglamenta la Inversión Privada en la Obra Pública. Diario El Telégrafo. Recuperado de http:// www.telegrafo.com.ec/economia/item/sereglamenta-la-inversion-privada-en-la-obrapublica-infografia.html.

Secretaría Nacional de Planificación y Desarrollo. (2013). Plan Nacional del Buen Vivir (20132017). Recuperado dehttp://documentos.senplades.gob.ec/Plan $\% 20$ Nacional $\% 20$ Buen $\% 20$ Vivir\%202013-2017.pdf. 